\title{
Preliminary Study on the Core Competencies of Full-time Master of Public Health in China
}

\author{
Y.J.QIN, Y.G.WANG* \\ Third Military Medical University, Chongqing, 400038, China \\ "Corresponding author
}

\begin{abstract}
Professional degree graduate education is emerging a reform wave in order to establish core competencies. In this paper, the characteristics of the core competencies of full-time Master of Public Health (MPH) graduate education, core competence indicators, curricula construction, and quality assurance measures were discussed, which lay a ground foundation for the eventual establishment of MPH core competencies index system suitable for China's national conditions.
\end{abstract}

KEYWORD: Master of Public Health (MPH); Core competency; Curricula system; China

\section{INTRODUCTION}

Professional degree is an important part of graduate and postgraduate education, which plays an important role in the social culture of high-level professionals. Currently, the development of professional degree graduate education is to establish the "core competencies" and "vocational competencies", which is a symbol of the thirdgeneration reform of medical education. Therefore, developing a training mode for full-time public health graduate in China has important practical significance. This paper preliminary discussed the characteristics of the core competencies of full-time $\mathrm{MPH}$, core competence indicators, curricula construction, and quality assurance measures, providing a reference for the training senior technical personnel in public health at our new era.

\section{DIFFERENT UNDERSTANDING IN MPH CORE COMPETENCIES}

Core competency refers to the different knowledge and skills, and the ability is highly recognized by members of the organization, which is essential to their own organization's efficient and orderly operation (Moser et al. 2008). This perspective emphasizes the integration ability that core competency is an aggregate includes knowledge, skills, abilities and personal qualities, which can bring competitive advantage, exists in the organization, is a key element for success of the organization and personal. As a profession and discipline, public health has its goal to improve human health and quality of life. Global health needs are changing and complex problems require interdisciplinary methods and system solutions, therefore, recognizing the core competencies in public health also experienced a continuous changing process.

In 1912, a study of foreign scholars provided a good example for contemporary public health education, and the report stressed the core concept of public health education is to train experts and leaders in health science (Fried et al. 2014). Twenty years ago, Fineberg et al. (1994) recommend that public health education should focus on training the core capabilities and expand training range of leaders and practitioners. America Disease Control and Prevention Center and other agencies and organizations established the Public Health Foundation (PHF), which proposed core competencies for public health professionals involved in eight areas, analysis and evaluation skills, policy development/project planning skills, communication skills, cultural competency skills, community practical skills, public health discipline skills, financial planning and management skills, leadership and systems thinking skills. The Association of Schools of Public Health (ASPH) has developed a comprehensive set of core academic competencies for MPH graduates, in addition to knowledge, public health professionals must also have information communication, cognitive and cultural differences, leadership, professional competence, planning, systematic thinking, as well as with knowledge related capabilities in public health.

Since 2001, China has launched MPH graduate education, and set the target for MPH education: high-quality training of public health and health 
management professionals applied talents to adapt to the socialist market economic development needs in our country (Wen et al. 2013). Degree Office of the State Council proposed a guidance training program, the training objectives of MPH education should require students to have a broader theoretical knowledge of modern public health and related disciplines, as well as more systematic professional knowledge; master the methods and skills in public health management, and be able to engage in the practical application; have the ability to apply the theories and methods into public health practice to identify, analyze and solve problems; have some scientific research capabilities, and grasp at least one foreign language (Wang, 2011). At present, there are no clearly defined criteria for core competencies in public health professionals in China, and only some ability evaluation criteria are pointed out, such as professional and technical qualifications, continuing medical education, post appointment, etc. The most representative ability standard is that raised for training public health management cadre in 2004, including basic management, information utilizing, self-learning, human-computer communication, financial management, human resources management, grasping policies and regulations, professional and technical guidance, information and Statistics, processing sudden public health incidents, and other basic abilities (Xia et al. 2011).

\section{THINKING OF CORE COMPETENCIES INDEX SYSTEM IN PUBLIC HEALTH EDUCATION}

The MPH Core Competency Development Project was completed in America in August 2006. There are five domains that address the traditional core areas of knowledge (Biostatistics, Environmental Health Sciences, Epidemiology, Health Policy and Management, and Social and Behavioral Sciences) currently required for MPH degrees, and seven interdisciplinary, cross-cutting domains (Communication and Informatics, Diversity and Culture, Leadership, Professionalism, Program Planning, Public Health Biology, and Systems Thinking) that were considered essential for contemporary public health practice (Calhoun et al. 2008). The Association of Schools of Public Health (ASPH) has developed a comprehensive set of core academic competencies for MPH graduates, emphasizing the participation between public health graduate students and public health practitioners, stressing the fundamental knowledge, attitudes, and skills that every MPH student should possess upon graduation, regardless of their major field (Moser, 2008).

Chinese scholar, Wen Shihao considered that MPH graduates must possess solid theoretical knowledge, and be able to apply their knowledge to solve public health problems (Wen et al. 2013).
Therefore, according to different research, students should have the following expertise: (1) applying the knowledge of preventive medicine to guide the practice of medicine, including hygiene, health statistics, epidemiology, toxicology and social medicine; (2) grasping the basic theoretical knowledge of biochemistry, physiology, cell biology, medical microbiology, etc. which are associated with public health; (3) mastering health services management, health economics, health law, health supervision, and other basic theoretical management knowledge in public health; (4) mastering healthrelated communication, behavioral medicine, medical psychology, health education and other basic theoretical knowledge; (5) grasping clinical medicine, education, psychology, and other theoretical knowledge relating to professional direction.

In our opinion, to build the MPH core competencies index system, we must recognize that public health is a practical science, that is, to solve the human health problems through discovering and analyzing problems. Therefore, public health workers are required to quickly discover the problems through statistical data, epidemic reporting, documentation and other information sources; then analyze the possible factors through synthesis, and induction ways; further using a variety of means, obtain a scientific basis and find solutions strategies eventually implemented in the real environment. Although not all public health workers need to complete all aspects of problem solving, the system should be presented in terms of education level. Therefore, MPH core competencies indicators should focus on developing public health leader talents, encouraging students to form the core concept on a research direction in public health sciences, guiding students to actively participate in the real-word public health challenges, so that the public health graduates can become comprehensive, interdisciplinary research workers, are able to solve the emerging public health problems rapidly.

\section{CONSTRUCTION PRINCIPLES OF CORE COMPETENCIES CURRICULUM SYSTEM}

Core competency is not the core curriculum or program development framework in teaching plan, but to provide the necessary knowledge and skills when emergency public health incidents are happened, these indicators provide a useful guide for related teaching courses, and are useful for MPH graduates to deepen understanding and explore new findings. Therefore, construction of curriculum systems should be different between universities, because of the differences in actual situation and special requirements of the core competence indicators. Degree Office of the State Council proposed a guidance training program, in which the main compulsory MPH courses include foreign 
language, health statistics, epidemiology, health management, health economics, etc., but there are no uniform regulations for other courses, and each teaching unit is independent according to the actual situation. At the current situation, MPH education program in schools does not form a complete curriculum system, has little courses in nature, culture, management and other interdisciplinary, even lacks training courses in practice. Compared with the developed countries in Europe and America, our MPH courses are little in catalogues, are not rich in contents, not strong in practicality, insufficient in the cultivation of students' abilities to solve the practical problems. Therefore, MPH education curriculum system must consider the following basic principles:

First, the graduates must have ideas, ambition, creativity, good communication skills, strong sense of team, are able to listen to different opinions, break through personal limitations and biases, find consensus, lead the research team to solve some complex problems, and achieve the best results.

Second, MPH students should have a firm understanding of the health challenges in 21stcentury, who can be leaders in domestic and global public health research. We need to train a lot of public health professionals who understand the global health challenges, can resolve the growing conflict between the growing public health needs and public health professional scarcities.

Third, it is necessary to cultivate interdisciplinary and comprehensive ability for public health professionals. Most of the public health problems are no longer (perhaps have never been) isolated and discipline-specific problems, therefore, our education needs to move well beyond the individual disciplinary perspective to an integrated, interdisciplinary approach.

Fourth, emphasize the practical and training contents. Research and practice in public health is necessary for students to understand basic disciplines and advanced techniques, and it is also the important basic aspects to train public health graduates.

Fifth, public health graduates should possess critical thinking skills and know how to apply it. In a complex and interconnected world, students must learn how to critically find the truth through resources, data and different information forms, have a comprehensive understanding for the situation, and thus solve the urgent public health issues.

Sixth, unity and cooperation is a key factor in solving complex problems. Knowing how to effectively work in a team is a key factor for success, therefore, unity and cooperation contents need to integrate into the teaching plans in future, and teambased research and practical skills should be cultivated for MPH students.

\section{QUALITY ASSURANCE SYSTEMS FOR CORE COMPETENCIES}

Postgraduate degree quality assurance measures are interrelated and mutually restricted operating mechanism established in the process of graduate education by professional degree education institutions, relevant quality assurance units and related agencies, in order to ensure and improve the quality of high-level professional training (Bie \& Tao, 2009). The coordination and mutual cooperation between the four main units of training organization, government, industry, and community assessment institutions are important for achieving postgraduate education objectives, improving training methods and quality assessment (Tian \& Zhang, 2013).

\subsection{Strengthen double tutor system}

Implementation of double tutor system, combing the advantage of theory tutor and practice tutor, can make students get the guidance of instructors in different academic expertise, broaden their knowledge horizons, improve their practical ability and the ability to engage in interdisciplinary research. At present, most instructors have developed more frequent business relationships with organization and industry in the project development process. It is not new for college instructors working in the enterprise, and some graduate students have already joined the research team, which create ideal conditions for double tutor system. When double tutor system is carried out, the theory tutor in university (first mentor) can get free from the practice session, focusing on the research direction, research programs, study guides and essay writing content for graduates; and the cooperating practice tutor (second mentor) can help students broaden academic horizons, accumulate clinical experience by taking practical training guidance. Because MPH core competencies focus on interdisciplinary research index system, it is difficult for one tutor to perform the tasks, so the establishment of a stable double tutor system can improve the quality of training courses. This double tutor system stresses the responsibility of first tutor, performing collective guidance, strengthening the ability of practical training and integrated services, enabling students to accept the influence of different knowledge structures and academic point, is conducive to core capacity building and innovative thinking.

\subsection{Strengthen collaborative innovation of production, learning and research}

At present, graduate cultivating models are gradually shifted from specialization on teaching and research, to collaborative innovation paradigm of production, learning and research. Future curriculum system will focus on interdisciplinary, open entrepreneurship 
education curriculum, cultivate the sense of innovation and entrepreneurship, encourage students to actively participate in teaching practice, social practice and other social activities, work as teaching and research assistants after obtaining the required credits. The joint training model between university, enterprise and research institute, is conducive for extending educational resources to the community, improve the unity of theory teaching, accelerate the accumulation of knowledge and innovation awareness, and improve the innovation ability of $\mathrm{MPH}$ core competencies.

\subsection{Open practice-oriented curriculum}

Teaching courses and practical aspects should combine together to actively guide the communication between school tutors and researchers in enterprises and institutions outside school. These tutors must work together to guide students in experiment and practice, take the problem found in practice as a teaching case, truly combine theoretical teaching and work practice. We should encourage students to participate in domestic and foreign-related conferences, actively organize various forms of academic exchange activities, ask students to be trained in production base of related fields, fully mobilize the enthusiasm of scientific research, and improve the application results of practice course.

\subsection{Actively promote the vocational qualification certification system}

Government and all sectors of society should support professional degree graduate education, especially, government personnel departments and labor management departments should actively promote the convergence of professional degree education and professional certification system, so that benign interactions are formed between them (Bie \& Tao, 2009). Schools and research institutes should initiatively adapt to the changes in economic and social development in need of the labor market, and strengthen cooperation with the professional certification departments; government administration should actively promote, coordinate and solve related problems between graduate education and professional certification, establish convenient channels for graduates to obtain various types of vocational qualification certificates.

\subsection{Evaluate the opinions of practice internships}

Practice internship is a critical stage for graduates from school to the community, and a transition phase towards jobs, therefore, opinions of internship positions play a key role for graduates quality supervision. Clinical practice and practice training will allow graduates to apply their learned theoretical and professional knowledge into the production practices flexibly, make the students feel that they are serving the community and contributing to the social life, which lay a solid foundation for graduates changing the roles in community and enhancing the core capabilities. Supervision opinions and evaluation measures of internships can enhance mutual communication and understanding between students and employers, enhance fitness for training students between school and training units, guide students to establish the right career coordinates.

\section{ACKNOWLEDGMENT}

This project was sponsored by Chinese Society of Academic Degrees and Graduate Education (B22013Y07-042), Chinese Medical Association (2012XW-42), and Chongqing Education Committee in China (yjg132018).

\section{REFERENCES}

[1] Bie, D.R. \& Tao, X.W. 2009. Reflection and innovation on quality assurance system of graduate education for professional degrees in China. Journal of High Education 30(3):42-48. (in Chinese)

[2] Calhoun, J.G., Ramiah, K., Weist, E.M. \& Shortell, S.M. 2008. Development of a core competency model for the master of public health degree. American Journal of Public Health 98(9): 1598-1607.

[3] Fineberg, H.V., Green, G.M., Ware, J.H. \& Anderson, B.L. 1994. Changing public health training needs: professional education and the paradigm of public health. Annual Review of Public Health 15:237-257.

[4] Fried, L.P., Begg, M.D., Bayer, R. \& Galea S. 2014. MPH education for the 21 st century: motivation, rationale, and key principles for the new Columbia public health curriculum. American Journal of Public Health 104(1):2330.

[5] Moser, J.M. 2008. Core academic competencies for master of public health students: one health department practitioner's perspective. American Journal of Public Health 98(9):1559-61.

[6] Moser, M., Ramiah, K. \& Ibrahim. M. 2008. Epidemiology core competencies of Master of Public Health students. Public Health Reports 123 (1):59-66.

[7] Tian, X.Z. \& Zhang, J. 2013. Improve quality of full-time professional degree education based on a "four-cycle" training mode. Journal of Graduate Education 3:82-86. (in Chinese)

[8] Wang, Y.J. 2011. Discussion on research hospital: connotation, characteristics and constructing pathway. Administration Journal of Chinese People's Liberation Army 18(5):403-406. (in Chinese)

[9] Wen, S.H., Ren, W.M., Ma, X.Q., Wang, J.L., Xu, F., Zhou, D. \& He, X. 2013. Study on training standard for MPH professional degree. Hospital Administration Journal of Chinese People's Liberation Army 20(2):178180. (in Chinese)

[10] Xia, Y.Y., Feng, X.Y., Wang, Y.X., \& Qiu, J.F. 2011. Analyzing the development of public health education in view of core competency of public health. Chinese Health Service Management 6:633-634. (in Chinese) 